\title{
Aa. Vv., «Bulletin Baudelairien», t. 39
}

\section{Alessandra Marangoni}

\section{(2) OpenEdition}

\section{Journals}

\section{Edizione digitale}

URL: http://journals.openedition.org/studifrancesi/27891

DOI: 10.4000/studifrancesi.27891

ISSN: 2421-5856

\section{Editore}

Rosenberg \& Sellier

\section{Edizione cartacea}

Data di pubblicazione: 31 décembre 2006

Paginazione: 628

ISSN: 0039-2944

\section{Notizia bibliografica digitale}

Alessandra Marangoni, « Aa. Vv., «Bulletin Baudelairien», t. 39 », Studi Francesi [Online], 150 (L | III) 2006, online dal 30 novembre 2015, consultato il 08 novembre 2020. URL : http://

journals.openedition.org/studifrancesi/27891; DOI : https://doi.org/10.4000/studifrancesi.27891

Questo documento è stato generato automaticamente il 8 novembre 2020.

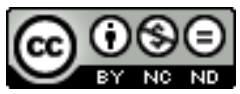

Studi Francesi è distribuita con Licenza Creative Commons Attribuzione - Non commerciale - Non opere derivate 4.0 Internazionale. 


\title{
Aa. Vv., «Bulletin Baudelairien», t. 39
}

\author{
Alessandra Marangoni
}

\section{NOTIZIA}

«Bulletin Baudelairien», t. 39, nn. 1-2, avril-décembre 2004, pp. 134.

1 Il trentanovesimo volume del «Bulletin Baudelairien» è dedicato alla memoria di Claude Pichois e si apre con ricordi di J. Dupont, J.-P. Avice, C. Guillard e M. Miner.

2 Il primo numero riporta il consueto censimento dell'amplissima bibliografia su Baudelaire relativa al 2004, nonché i supplementi ai censimenti bibliografici degli anni 2002 e 2003. Strumenti fondamentali per lo studioso, anche perché nel caso in cui non compaia il nome di Baudelaire nel titolo segnalato, vengono fornite le pagine dove è nominato e le motivazioni che lo chiamano in causa.

Il secondo numero esordisce con un articolo di Ph. C. DUBOIS su Baudelaire et ses curiosités culinaires, titolo in apparenza digressivo che vuole in realtà portare l'attenzione sull'allargamento dell'orizzonte lessicale e poetico nei petits poèmes en prose, in virtù di incursioni nell'argomento culinario. La dimostrazione parte dal rinnovamento del vocabolario gastronomico all'inizio dell'Ottocento, passa attraverso la Physiologie du goût di Brillat-Savarin e giunge fino al protagonista di A rebours, il quale declinerà il poème en prose secondo una terminologia di tipo gastronomico per la distillazione e condensazione che comporta. "Enivrez-vous" viene letto, in modo inedito, come possibile risposta a una massima di Brillat-Savarin («celui qui s'énivre ne sait pas boire») e inserito al culmine di una «recherche d'une esthétique spécifique de l'ivresse» (p. 73) intrapresa sulle orme di Balzac.

4 Segue Baudelaire and the Trauma of Modernity di D. SANYAL che fa il punto sulle diverse letture della modernità di Baudelaire (specie in lingua inglese) nate sulla scia della critica storico-sociologica di Benjamin e della teoria psicoanalitica del "trauma". 
Emerge il vantaggio di sradicare Baudelaire dall'immagine di seguace de l'art pour l'art, ma anche il rischio di appiattirlo alla realtà del suo tempo.

5 T. RAISER esplora l'esile spazio del pittore americano George Catlin nei Salons del $1846 \mathrm{e}$ del 1859 e il posto di maggior rilievo che sembra invece occupare nell'idea di modernità di Baudelaire: George Catlin, the new World, and Modernity in Baudelaire's Art Criticism. Con precisi rinvii testuali, viene infatti supposto che alcune affermazioni del Peintre de la vie moderne possano trovare un referente non tanto in Constantin Guys, ma proprio in George Catlin.

Prosegue le ricerche iniziate alla Vanderbilt University su C.A. Bristed, Poe e Baudelaire l'articolo di P.A. WARD (New notes on C.A. Bristed, Poe and Baudelaire): il giornalista americano, corrispondente parigino per "The Spirit of the Times", possedeva una copia delle Fleurs du Mal del 1857, era al corrente della controversia legata alla loro pubblicazione e doveva sapere della traduzione, da parte di Baudelaire, delle Aventures d'Arthur Gordon Pym. Avendo incrociato e forse personalmente conosciuto Poe a New York, è più che probabile che Baudelaire e Asselineau gli abbiano fatto visita a cavallo tra il 1851 e il 1852, per parlare del grande scrittore americano. Incontro già ipotizzato da J.S. Patty, sulla base della biografia di Asselineau.

7 A conclusione, un ringraziamento, in memoriam, a R. POGGENBURG per il contributo dato agli studi su Baudelaire alla Vanderbilt University, dove si pubblica il «Bulletin Baudelairien». 